\title{
"Measuring the Performance of Saudi Domestic Airports Using Data Envelopment Analysis(DEA)"
}

\author{
Saleh Abdul Rahman Bin Sabaan \\ dr_binsabaan@yahoo.com \\ King Abdul Aziz University,Jeddah ,Saudi Arabia \\ Fahd WaslAlosaimi \\ Researcher,EMBA Student \\ fahdosaimi@gmail.com
}

Associate professor,Faculaty Of Economic And Adminestration ,King Abdul Aziz University

\begin{abstract}
The following research is aimed at evaluating the performance of domestic airports in Saudi Arabia with the help of Data Envelopment Analysis (DEA), based on outputs and inputs of the airports . A total of 21 domestic airports in Saudi Arabia were evaluated. The inputs were represented by such variables as Total Airport Capacity, Operation Cost and Number of Routs, whereas Numbers of Movement, Passengers and Cargo were considered as outputs.

According to the results of the research, only ten airports of those under study are purely technically efficient. Eleven airports were found inefficient. The Super efficiency model was used to conduct ranking of efficient airports
\end{abstract}

\section{Council for Innovative Research}

Peer Review Research Publishing System

Journal: International Journal of Management \& Information Technology

Vol 10, No 3

editorsijmit@gmail.com

www.ijmit.com 


\section{Introduction}

Airports are associated with the gateway to the country as they make it open and convenient both for both trade and tourism. Airports generate their revenue from the fees, which should be paid for plane landings and take-offs; rent, paid by retail stores, which lease some space of the terminals etc. Major expenses of the airports are connected with maintaining the terminals and runways, utilities (e.g., water, electricity) and employees' salaries.

Customers of the airports can be divided into two major groups, namely passengers and different companies' airlines. The needs of the former include roadways, reliable and convenient public transportation to and from the airport, spacious parking lots, and comfortable areas for ticketing, check-in and baggage handling. Moreover, passengers appreciate operation of variety extra services, including those provided by duty free shops, cafes and restaurants.

Airlines need space for airplanes, sufficient number of quality facilities for routine maintenance, jet fuel and places, where flight crews can stay while on ground. Airports should have enough space and facilities, so that all aforementioned needs are satisfied.

An efficient airport is capable of providing economic catalysts that enable the local and regional economy to thrive and improve the quality of life in the region (Oum et al.,2008).

In terms of assessing performance, the term 'efficiency' refers to such a level of performance, which manages to use the lowest amount of inputs to create the greatest amount of outputs. It is easier to reach the level of performance, which may be characterized as effective, than the one, which lets a professional describe the performance as efficient as effectiveness refers only to capability of reaching particular results without any inputs-related requirements.

Air transport sector in Saudi Arabia is governed by a General Authority for Civil Aviation (GACA). The Authority was established by the Council of Ministers of the Kingdom of Saudi Arabia by Decision No 13 Dated 17-1-1425, which transformed the Presidency of Civil Aviation into a public body, and provided the newly formed body with financial and administrative independence.

Such indicators as passenger and traffic, together with intensity of aircrafts' movement are used by General Authority of Civil Aviation to assess performance of the airports. Aforementioned indicators are reflected in the Authority's annual reports. Researchers tend to use them as outputs (using such indicators as land area, number of runways, terminal area, and operating expenses as inputs) to measure and assess performance of the airports.

The following research is aimed at evaluating the performance of Saudi Arabian domestic airports with the application of Data Envelopment Analysis (DEA), based on multiple inputs, utilized by airports and multiple outputs they produce. DEA is a wide-spread nonparametric method, which was originally designed to measure productive efficiency of decision-making units. Different types of DEA models were developed to ensure quality analysis of the efficiency of different DMUs. In this research several DEA models were used. Moreover, the super efficiency model was used to ensure not only distinguishing efficient airports, but to rank them. Modern level of the development of computer technologies allows researchers to use special software to solve DEA models. Current research uses the Excel Solver to solve DEA models. The usage of Excel Solver and specially-designed code allows automating the process of DMUs' efficiency analysis and analyze large numbers of DMUs with the application of multiple inputs and outputs.

\section{Research objectives}

The basic objectives of the research are:

To measure the relative efficiency of 21 local airports in Saudi Arabia

To calculate an extent to which the inputs should be decreased (or outputs should be increased), so that airports, which were found inefficient, reach the lowest efficiency limit

To identify the causes and degrees of inefficiency in airports, which were found inefficient

To apply super efficiency model to rank efficient airports

\section{Aviation and airports in Saudi Arabia}

\subsection{Aviation in Saudi Arabia}

As it was already mentioned in the introduction to the research paper, aviation sector in Saudi Arabia is governed by the General Authority for Civil Aviation (GACA).

The civil aviation system and the tasks of the General Authority for Civil Aviation (GACA) are determined in the regulation 13-5-1426H (20-6-2005G). It created the legal framework for the development of air transportation sector and validated current policy-making and strategic objectives, including those related to licensing the activities of carriers and determining National Air and local economic impact, which may result from aforementioned licenses. Regulations of Civil Aviation were adopted in 2006. They contain rules and procedures for the regulation of commercial licensing and post-licensing of air carriers in the Kingdom. The regulations include, among all, the licensing procedures for scheduled domestic and international scheduled air carriers, exclusive air cargo carriers and charter carriers for passengers.

In its activities the Authority concentrates on developing the secured airspace, which will meet the highest standards of safety and services on offer. To reach this ambitious vision, GACA adopted a range of policies, aimed at ensuring 
availability of air transportation service to all the citizens in the Kingdom, implementation of the principle of equality and protected competition, enhancing the development of airports and related facilities, and ensuring continuity of air transportation services.

Importance of successful implementation of GACA activities is called forth by the significant role of airports in socioeconomic development of the Kingdom. Saudi Arabia is one of the largest states in Western Asia by land area (2149690 kilometers 2) and second largest in the Arab world. In 2012 the population of the country was estimated to constitute more than 29 million people. Such factors as country's geographical position between Asia, Africa and Europe, large area, significant number of population, active development of economy and trade, and the presence and ever increasing popularity of Muslim holy places (Makkah and Medina) predetermined importance of ensuring activeness, reliability and accessibility of air transportation within the state.

\subsection{Airports and their performance}

The Kingdom of Saudi Arabia has four international airports: King Khalid International in Riyadh, King Fahd International in Dhahran, the King Abdulaziz International Airport in Jeddah and Prince Muhammad bin Abdulaziz Airport in Madinah. Moreover, 24 regional and local airports function in the Kingdom. A majority of them will be considered in this study. Most important non-international airports in Saudi Arabia are Abha, Tabuk (Prince Sultan) and Taif airports. As it was already referred to in the introduction, airports are designed to satisfy the needs of two large groups of consumers, whose needs and interests do not match. So, airports require lots of inputs run their everyday operations. For the purposes of this research such inputs as operating costs, annual passenger capacity and the number of routes. In the future it is also worth taking into account such important inputs as the number of gates, terminals' area and the number of staff should be taken into account. Utilization of inputs allows airports to produce outputs, which are most often associated with the number of flights, served passengers and total weight of cargo.

Nowadays air sector in the Kingdom is reported to demonstrate steady growth. According to Statistical Yearbook (2011), published by GACA, the number of passengers in Saudi Arabia reached more than 54 million passengers in 2011, an increase of $13.6 \%$ over 2010. A significant growth was demonstrated was showed by domestic airports. According to the Yearbook's (2011) data, in 2011 domestic airports experienced a healthy 19\% increase in the number of passengers, 7\% in the quantity of scheduled flights and $5 \%$ increases in cargo. Most significant amount of traffic was reported by such domestic airports. Most significant growth trends with regard to the number of flights was recorded in such domestic airports as Al-Gurayat and Rafha, which accounted for 32.1 and 26.2 growth per cent. Nonetheless, most important position still belongs to Abha. The same trends are true for the number of passengers-related trends. In terms of increase in the amount of carried cargo the first position belongs to Al-Ahsa, which is followed by Al-Baha.

As the number of passengers, served during the year, the number of aircraft's movements and total weight of cargo, carried over the yearly period are major outcomes of airports' activities, they were selected as outputs for the research on the efficiency of the domestic airports in Saudi Arabia. By-turn, inputs were selected with respect to most important resources, which were utilized by the airports over the period under study. They are operating costs in SR, annual passenger capacity and the number of routes.

\section{Research methodology}

In this study a DEA methodology was applied to measure the performance of Saudi local airports for the year of 2011 . The methodology was applied to 21 Saudi local airports. Multiple DEA models were applied to measure airports' relative efficiency. The methodology of the following research is:

Focusing on revising sources related to measuring performance of airports with the usage of DEA.

Providing the methodology and models used to perform the analysis and the results of each DEA model's application.

\subsection{Literature review}

The research includes a review of literature related to studies, which include the application of DEA models to measuring performance of airports.

Guillen and Lall (1997) pioneered the use of Data Envelopment Analysis techniques to study efficiency in the airport sector. They used data from 21 US airports over the period 1989-1993. Using this dataset they defined airports as producing two different classes of services: terminal services and movements. Thereafter the researchers computed two different FEA frontiers for U.S. airports, one for each of the two services, mentioned above.

In their study Martin and Roman (2001) used DEA method in order to evaluate the performance of Spanish airports before privatization. Data from 1997 was used to assess 37 airports in the country. The inputs were given as expenses related to workmanship, capital and material, while outputs included air transport activities, number of passengers and size of cargo in tons. Number of runways, number of gates, terminal area and number of employees were not used due to insufficient data. The study found that 11 airports were $100 \%$ efficient. The ranking of efficient airports was not conducted.

Bazargan and Vasigh (2003) evaluated 45 USA airports using DEA model, namely CCR methods introduced by Charnes, Cooper \& Rhodes. The inputs were operation expenses, on-operation expenses, number of runways and number of gates, whereas the outputs were determined as the number of passengers, number of air transport activities, number of other activities, aviation revenues, non-aviation revenues, and percentage of timely operations. 
Yoshida and Fujimoto (2004) used the data of year 2000 to measure the performance of 67 Japanese airports using the input oriented model. In their study the inputs were the length of runway, size of terminal, transport expenses and number of employees, whereas the outputs were passenger density, cargo carriage, and flight activities. They found out that airports with bigger terminals and fewer users had lower efficiency scores.

Joseph Sarkis (2000) focused on evaluation of 44 major U.S. airports using data envelopment analysis and some of its recent developments. Various airport characteristics were evaluated to determine their relationship to an airport's efficiency. Efficiency measurement was based on four resource input measures including airport operational costs, number of airport employees, gates and runways, and five output measures including operational revenue, passenger flow, commercial and general aviation movement, and total cargo transportation.

In 2001 a comprehensive study of efficiency of a number of European and non-European airports was conducted by Adler, $\mathrm{N}$. and Berechman, J. The main objective of their paper was to develop a model, which can help to determine relative efficiency and quality of airports. The study was conducted from the viewpoint of airlines, whereas lots of previous studies were based on subjective data, obtained from passengers. Principal component analysis was used to supplement DEA model in this study. Results of the study showed high rates of relative efficiency for the airports of such cities as Milan, Geneva and Zurich. Lowest scores were received by Charles de Gaulle, Athens and Manchester airports.

The innovative study by Barros\&Dieke (2008) represents a two-stage methodology of evaluating airports' efficiency, initially based on the application of DEA model. In the first stage of analysis authors used DEA to single out most efficient airports in Italy. In the second stage of research authors bootstrapped DEA scores with the help of truncated method. This study allowed both distinguishing efficient airports and ranking them.

Another study of efficiency of Italian airports with the application of DEA model was conducted by Curi, Gitto, \& Mancuso (2008). The main objective of the study was to single out the best performers among 19 Italian airports, basing on the data, obtained over the period 2000-2004 and emphasize variables, controlled by management, which are capable of helping to increase efficiency of airports' performance. The study was conducted against the background of privatization of airports. It was found out that airports tended to react positively to changes, called forth by privatization.

In his study HabipKoçak (2011) used DEA to measure the efficiency of 44 airports in Turley. For this purpose, operation expenses, number of personnel, flight traffic and number of passengers were taken as input variables, while the number of passengers/area, flight traffic/runway, total load and operation expenses were taken as output variables The study indicated that only 7 airports among those under study were efficient.

Syamsul et al. (2010) used DEA to assess the performance of 20 Malaysian airports during 5 years (2005-2009). They divided the measurement into two models for two basic classes of services (the terminal services and the movements). The inputs for terminal services were the numbers of employees, runways, gates and check in desks, while the outputs included tons of air cargo handled and indicators related to aircrafts' movements (landings and takeoffs). For movements they selected one output aircraft movement and three inputs number of runways, employees and runway area. CCR model, BCC model, the Cross-Efficiency DEA model and the Super-Efficiency DEA model were applied.

In their study Psaraki and Kalakou (2010) assessed the efficiency of Greek airports using DEA. They applied the methodology to landside and airside separately. In each case, different inputs and outputs are used and alternative DEA models are applied. They found that the airports that serve more movements are found to be more efficient than those that serve fewer movements.

\subsection{Data Envelopment Analysis (DEA).}

DEA is a non-parametric method, which uses a linear programming (LP) to measure the relative efficiency of DMUs (decision making units) with similar multiple inputs and outputs. The relative efficiency of a DMU is the ratio of the sum of its weighted outputs to the sum of its weighted inputs.

Data Envelopment Analysis methodology was developed by Farrell (1957) and then improved by Charnes, Cooper, and Rhodes (1978); this methodology has been widely applied to the efficiency measurement of many organizations. The most widely used DEA models are the CCR and the BCC models. The main difference between the two models lies in the assumption or RTC (Return To Scale). The CCR model assumes constant return to scale (CRS), whereas the BBC model assumes variable return to scale (VRS).DEA models can be either input-oriented (i.e. minimizing the input without any change of the output), or output-oriented (i.e. maximizing the output without any change of the input).

In this research output-oriented CCR and BCC models were applied to analyze the Saudi domestic airports efficiency and to find out how to produce the maximum possible airports outputs without using more inputs. A super efficiency model was used to rank efficient airports. The output-oriented model was chosen because the researcher believes that maximize the output is a primary goal of airport operations. 


\subsubsection{CCR Model (CRS)}

CCR model is the first DEA model which developed by Charnes, Cooper and Rhodes (1978). CCR calculates the total efficiency of an organization by accumulating the technical efficiency and scale efficiency. The model aims at maximizing the output; the objective function is given below:

$$
\begin{aligned}
& \begin{array}{l}
\phi^{*}=\max \\
\text { Subject to }
\end{array} \\
& \sum_{j=1}^{n} \lambda_{j} x_{i j} \leq x_{i 0} \mathrm{i}=1,2, \ldots \ldots, \mathrm{m} \quad \text { number of inputs } \\
& \sum_{j=1}^{n} \lambda_{j} y_{r j} \geq \phi y_{r 0} \mathrm{r}=1,2, \ldots \ldots, \mathrm{s} \quad \text { number of outputs } \\
& \lambda_{j} \geq 0 \quad \text { is the weight to be determined by solving the model } \\
& \lambda_{0} \quad \text { number of } \mathrm{DMUs} \\
& \text { Where the efficiency of DMU under evaluation }=\frac{1}{\phi *}
\end{aligned}
$$

\subsubsection{BCC model (VRS)}

BCC model was developed by Banker, Charnes and Cooper (1984). It measures the pure technical efficiency(PTE) under the assumption that output varies according to scale. The objective function is:

$$
\phi^{*}=\max \phi
$$

Subject to
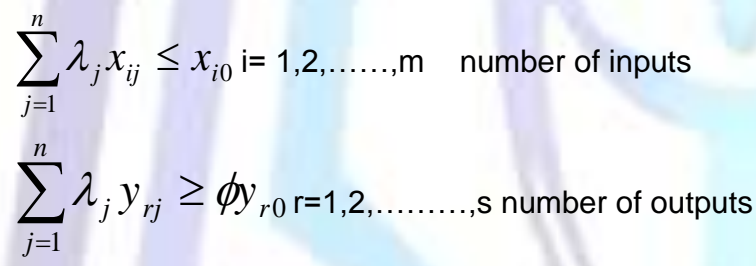
$\lambda_{j} \geq 0$
$j=1,2, \ldots, n$ number of DMUs

$$
\sum_{j=1}^{n} \lambda_{j}=1
$$

$\lambda$ is the weight to be determined by solving the model

The efficiency of DMU under evaluation $=\frac{1}{\phi^{*}}$

The main difference between CCR and BCC models lies in the constraint $\sum_{j=1}^{n} \lambda_{j}=1$ in BCC model. 


\subsubsection{Slacks model}

The model, used to calculate the inputs-outputs slacks is

$$
\begin{gathered}
\operatorname{Max} \sum_{j=1}^{n}{ }_{i}^{-}+\sum_{j=1}^{n}{ }_{r}^{+} \\
\sum_{j=1}^{n} \lambda_{j} x_{i j}+{ }_{i}^{-}=x_{i 0} \\
\sum_{j=1}^{n} \lambda_{j} y_{r j}-\underset{r}{+}=\phi^{*} y_{r 0} \\
\sum_{j=1}^{n} \lambda_{j}=1 \\
\lambda_{j}, s_{i}, \underset{r}{+} \geq 0
\end{gathered}
$$

Where $\square$ *is the relative efficiency, calculated from 1 or 2 .

$$
\text { is the weight to be determined by solving the model }
$$

$\underset{i}{S}$ Input Slack and $\underset{i}{S}$ Output Slack.

A DMU is said to be full efficient if and only if $\left(\phi^{*}=1\right.$ and $\underset{i}{S}=\underset{i}{S}=0$ )

\subsubsection{Super efficiency model}

The CCR and BCC models present the efficient and inefficient DMUs. However as all the efficient DMUs have equal efficiency score of 1 , it is impossible to rank those DMUs. To overcome this issue Andersen and Petersen (1993) proposed the super efficiency model to rank the efficient DMUs. Thereafter an improved model was introduced by J.Zhu (2003). It measures possible increases in inputs and decreases of outputs in terms of organization's not losing its efficiency. The super efficiency model looks like the DEA model. The main difference in the models lies in the fact that under super efficiency model the DMU under evaluation is excluded from the reference set.

In this model the efficient DMU can take a score of greater than or equal to one, so that the ranking of efficient DMUs becomes possible. On the while the efficiency scores of the inefficient DMUs remain the same as under the DEA model.

Figure 1 represents an output oriented the super-efficiency model. The efficiency frontier consists of the line segment connecting DMUs A, B and C. To apply the super-efficiency model to DMU B, it should be excluded from the reference set. This will construct a new frontier, consisting of the broken line connecting DMUs $\mathrm{A}$ and $\mathrm{C}$.

The super-efficiency of DMUB $=\frac{U_{B}^{B}}{O^{*}}>1$, which means that $D M U B$ can reduce its output with the amount of $\left(\frac{O B-O B^{*}}{O B^{*}}\right)$ and remain efficient. 


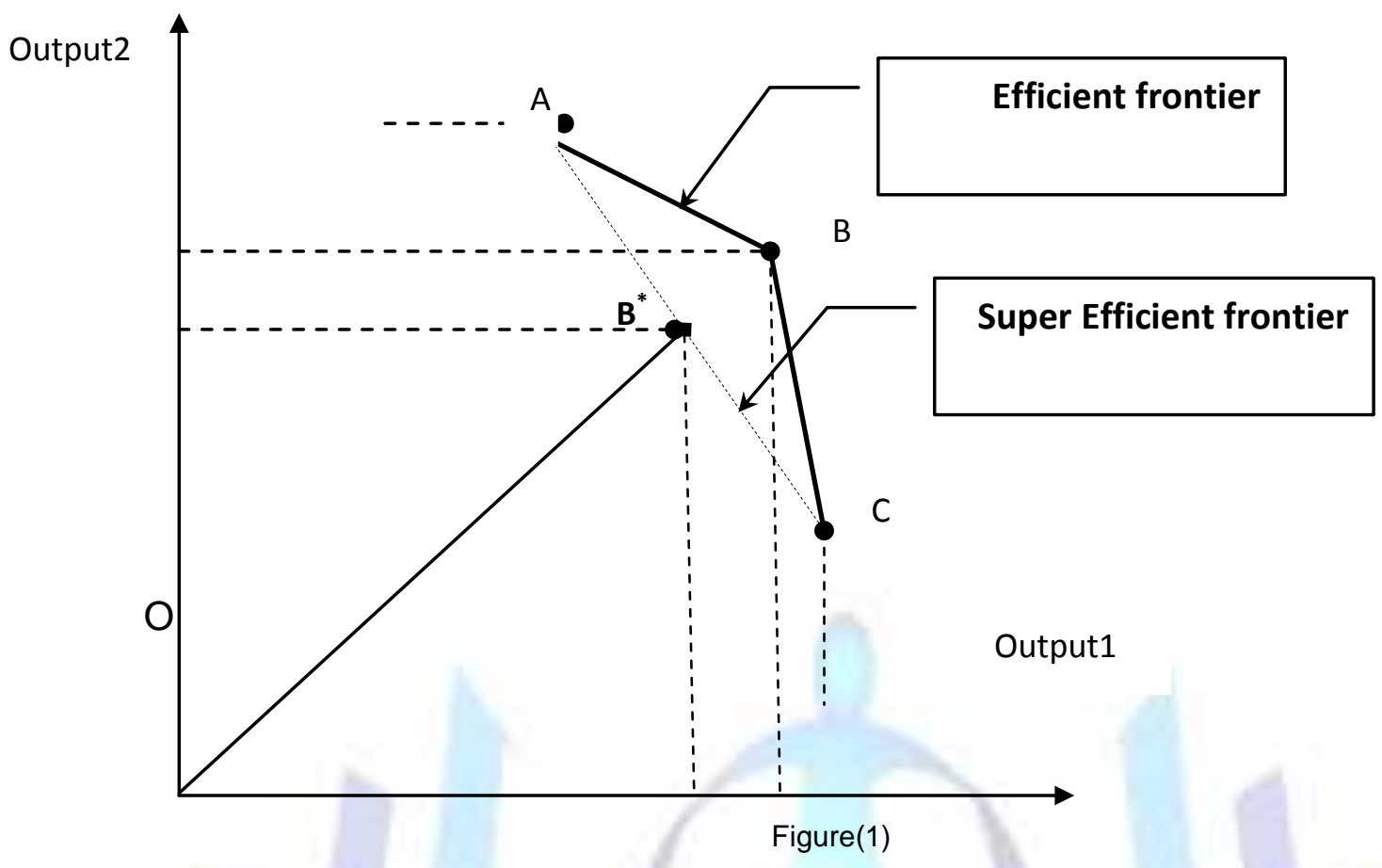

\section{Scope of the research}

Determination of inputs and outputs and the number of DMUs is highly important for successful application of DEA. The relationship between the inputs, outputs and the number of decision-making units should satisfy this condition, $\mathrm{n} \geq$ max \{rxs, 3(rxs)\} where $n$ is the number of DMUs, $r$ is the number of inputs and $s$ represents the number of outputs (Banker et al., 1984).

In this research 3 inputs and 3 outputs have been selected and a total of 21 domestic airports have been used as DMUs, so the minimum DMUs, required for the application of DEA models was exceeded. The researcher used the data for the year 2011 highlighted in the General Authority for Civil Aviation annual report.

The inputs which cover the resources utilized by the airport were determined as:

1. Operating costs in SR. Operating costs are the expenses, which are connected with the operation of business. Business operating costs include fixed costs (which do not change despite the changes in operations) and variable costs (they depend on the volumes of production)

2. Annual passenger capacity. Annual passenger capacity refers to the number of passengers that airport can serve in one year

3. Number of routes.

The outputs which represent the major outcome resulted from airport operations are:

1. Total number of passengers, served during the year in.

2. The number of aircraft movements during the year.

3. Cargo (Total weight of cargo during the year in tons, carried by air transport.

Table 1: Descriptive statistics for input and output variables

\begin{tabular}{|l|l|l|l|l|}
\hline Variable & Minimum & Maximum & Mean & $\begin{array}{l}\text { Standard } \\
\text { Deviation }\end{array}$ \\
\hline Operation Cost & 6342421 & 12995450 & 9672961 & 1666585 \\
\hline Airport Capacity & 92000 & 1500000 & 588190.5 & 450151.9 \\
\hline Routes & 3 & 14 & 6.4 & 3.1 \\
\hline $\begin{array}{l}\text { Total No Of } \\
\text { Passengers }\end{array}$ & 14711 & 1692049 & 323957.6 & 395205.2 \\
\hline Cargo & 2.7 & 3632.9 & 692.9 & 1057.6 \\
\hline Movements & 238 & 14412 & 3425.6 & 3327.8 \\
\hline
\end{tabular}


The correlation was examined to measure the relation between the inputs and outputs. The correlation matrix (shown below) represents strong correlation rates between inputs and outputs.

Table2: Correlation Matrix

\begin{tabular}{|c|c|c|c|c|c|c|}
\hline & $\begin{array}{c}\text { Operation } \\
\text { cost }\end{array}$ & $\begin{array}{c}\text { Airport } \\
\text { Capacity }\end{array}$ & Routes & $\begin{array}{c}\text { Total No of } \\
\text { passenger }\end{array}$ & Cargo & $\begin{array}{c}\text { No: of } \\
\text { movement }\end{array}$ \\
\hline $\begin{array}{c}\text { Operation } \\
\text { cost }\end{array}$ & 1.00000 & & & & & \\
\hline $\begin{array}{c}\text { Airport } \\
\text { Capacity }\end{array}$ & 0.36967 & 1.00000 & & & & \\
\hline Routes & 0.59435 & 0.67600 & 1.00000 & & & \\
\hline $\begin{array}{c}\text { Total No of } \\
\text { passenger }\end{array}$ & 0.60225 & 0.80923 & 0.71571 & 1.00000 & & \\
\hline Cargo & 0.58683 & 0.81425 & 0.75359 & 0.93531 & 1.0000 & \\
\hline $\begin{array}{c}\text { No: of } \\
\text { movement }\end{array}$ & 0.59104 & 0.82719 & 0.73066 & 0.99321 & 0.9260 & 1.00000 \\
\hline
\end{tabular}

\section{Analysis and Results}

\section{6-1. Efficiency Index}

An Excel Solver has been used to solve DEA models. The usage of Excel Solver and specially-designed code allows automating the process of DMUs' efficiency analysis and analyze large numbers of DMUs with the application of multiple inputs and outputs.

Table 3 reports the results of application of CCR and BCC models to the data on domestic airports in Saudi Arabia. The results indicate that the average index of technical, pure and scale efficiency account for $59.29 \%$. $76.82 \%$ and $78.92 \%$ respectively.

The results of the analysis of efficient airport's performance can be summarized as follows:

a. 10 airports (47.62\%) are purely technically efficient (PTE). These airports are Abha, Giezan, Beishah, Al-Baha, WadiAldawaser, Najran, Al-Qaisomah, Al-Jouf, Yanbu and Al-Dawadmi.

b. $\quad 4$ airports (19.05\%) are technically efficient (TE) which means that they are both pure technical and scale efficient. These airports are Abha, Gizan, , Beishah and Al Jouf. These airports are operating at the most productive scale size.

c. 6 airports which are (PTE) but not (TE) have been operating efficiently except the effect of scale. These airports are Al-Baha, WadiAldawaser, Najran, Al-Qaisomah, Yanbu, and Al-Dawadmi.

d. 11 airports fail both to operate at proper scale and use their resources effectively. These airports are Tabouk, Taife, Qaseim, Haiel, Sharorah, Teraif, Araar, Alwajh, Rafha, Alahsa and Alqurayat.

e. 11 airports are working above average (CCR) efficiency, 14 airports above average (VRS) efficiency and 12 airports above average (SE).

f. 17 airports have IRS which means that these airports can reach the efficiency frontier and on an optimal scale by managing their outputs.

Table 3:Results

\begin{tabular}{|l|c|c|c|c|}
\hline Airport & CRS Score & VRS Score & Scale Efficiency & Return To Scale \\
\hline ABH & $100 \%$ & $100 \%$ & $100 \%$ & CRS \\
\hline TUU & $62.42 \%$ & $65.35 \%$ & 95.52 & Increasing \\
\hline TIF & $51.84 \%$ & $54.61 \%$ & $94.91 \%$ & Increasing \\
\hline ELQ & $61.76 \%$ & $83.71 \%$ & $73.78 \%$ & Increasing \\
\hline HAS & $79.69 \%$ & $95.70 \%$ & $83.27 \%$ & Increasing \\
\hline GIZ & $100 \%$ & $100 \%$ & $100 \%$ & Constant \\
\hline ABT & $70.47 \%$ & $100 \%$ & $70.47 \%$ & Increasing \\
\hline WAE & $60.56 \%$ & $100 \%$ & $60.56 \%$ & Increasing \\
\hline
\end{tabular}




\begin{tabular}{|c|c|c|c|c|}
\hline SHW & $38.24 \%$ & $47 \%$ & $81.37 \%$ & Increasing \\
\hline TUI & $27.22 \%$ & $31.61 \%$ & $86.12 \%$ & Increasing \\
\hline $\mathrm{BHH}$ & $100 \%$ & $100 \%$ & $100 \%$ & Constant \\
\hline RAE & $72.61 \%$ & $96.20 \%$ & $75.48 \%$ & Increasing \\
\hline EJH & $24.84 \%$ & $36.24 \%$ & $68.49 \%$ & Increasing \\
\hline RAH & $31.43 \%$ & $56.48 \%$ & $55.65 \%$ & Increasing \\
\hline EAM & $78.27 \%$ & $100 \%$ & $78.27 \%$ & Increasing \\
\hline AQI & $36.68 \%$ & $100 \%$ & $36.68 \%$ & Increasing \\
\hline AJF & $100 \%$ & $100 \%$ & $100 \%$ & Constant \\
\hline HOF & $3.92 \%$ & $4.18 \%$ & $93.83 \%$ & Increasing \\
\hline URY & $53.15 \%$ & $79.34 \%$ & $66.99 \%$ & Increasing \\
\hline YNB & $81.24 \%$ & $100 \%$ & 81.24 & Increasing \\
\hline DWD & $10.74 \%$ & $100 \%$ & $10.74 \%$ & Increasing \\
\hline Average & $59.29 \%$ & $76.82 \%$ & $78.59 \%$ & \\
\hline $\begin{array}{l}\text { Efficient } \\
\text { Airports }\end{array}$ & $\begin{array}{c}4 \\
(19.05 \%)\end{array}$ & $\begin{array}{c}10 \\
(47.62 \%)\end{array}$ & $\begin{array}{c}4 \\
(19.05 \%)\end{array}$ & \\
\hline $\begin{array}{l}\text { In Efficient } \\
\text { Airports }\end{array}$ & $\begin{array}{c}17 \\
(80.95 \%)\end{array}$ & $\begin{array}{c}11 \\
(52.38 \%)\end{array}$ & $\begin{array}{c}17 \\
(80.95 \%)\end{array}$ & \\
\hline
\end{tabular}

\subsection{Input and Output Slacks for VRS model}

Table 4 reports the input and output Slacks. It indicates that airports like ( Tabouk Airport) have an excess in the route with an amount of $3 . .31$ and a shortage in the total number of passengers by the amount of (169052). This means that if the number of routes decreased and the passengers increased, the airport would become $100 \%$ technically efficient. This can be applied to all other inefficient airports.

Table 4:linput and Output Slacks

\begin{tabular}{|c|c|c|c|c|c|c|}
\hline & \multicolumn{3}{|c|}{ Inputs } & \multicolumn{3}{c|}{ Outputs } \\
\hline Airport & $\begin{array}{c}\text { Airports } \\
\text { Capacity }\end{array}$ & Routes & $\begin{array}{c}\text { Operation } \\
\text { cost }\end{array}$ & $\begin{array}{c}\text { No of } \\
\text { Movements }\end{array}$ & Cargo & Passengers \\
\hline ABH & 0 & 0 & 0 & 0 & 0 & 0 \\
\hline TUU & 0 & 3.31 & 0 & 0 & 0 & 169052 \\
\hline TIF & 0 & 2.11 & 0 & 0 & 1057.45 & 159958.61 \\
\hline ELQ & 0 & 0 & 0 & 0 & 0 & 59104.47 \\
\hline HAS & 0 & 1.56 & 0 & 1820.7 & 0 & 308073 \\
\hline GIZ & 0 & 0 & 0 & 0 & 0 & 0 \\
\hline ABT & 0 & 0 & 0 & 0 & 0 & 0 \\
\hline WAE & 0 & 0 & 0 & 0 & 0 & 0 \\
\hline SHW & 0 & 1.1 & 0 & 0 & 641.11 & 200101 \\
\hline TUI & 0 & 2.51 & 0 & 0 & 402.22 & 200144.66 \\
\hline BHH & 0 & 0 & 0 & 0 & 0 & 0 \\
\hline RAE & 0 & 1.26 & 0 & 528.68 & 0 & 62190.43 \\
\hline EJH & 0 & 1.65 & 0 & 0 & 407.53 & 119320 \\
\hline RAH & 0 & 0 & 539094 & 0 & 37.10 & 54881 \\
\hline
\end{tabular}




\begin{tabular}{|c|c|c|c|c|c|c|}
\hline EAM & 0 & 0 & 0 & 0 & 0 & 0 \\
\hline AQI & 0 & 0 & 0 & 0 & 0 & 0 \\
\hline AJF & 0 & 0 & 0 & 0 & 0 & 0 \\
\hline HOF & 0 & 1 & 0 & 0 & 939.83 & 14445 \\
\hline URY & 0 & 0 & 1207200 & 411.76 & 0 & 51251 \\
\hline YNB & 0 & 0 & 0 & 0 & 0 & 0 \\
\hline DWD & 0 & 0 & 0 & 0 & 0 & 0 \\
\hline
\end{tabular}

\subsection{Input and Output Slacks for CRS Model}

Table (5) reports the input and output Slacks according to scale. It shows the amount of inputs that should be decreased and the amount of outputs that should be increased to make the airport 100\% Scale efficient. For example Al-Dwadmi Airport has an excess in Operating Cost and Annual Capacity with an amount of (4087759 SR) and a shortage in Cargo and Passenger with an amount of (883.1 Tons) and (286052 passengers) respectively. This means that airport's management should reduce the operating cost by amount of ( $2433504.5 \mathrm{SR}$ ) and find solutions to achieve the target of the number of passengers that is equal to (300763) passengers per year, and the cargo to 885.79 Tons to reach the efficient frontier.

Table 5

\begin{tabular}{|c|c|c|c|c|c|c|}
\hline \multirow[b]{2}{*}{ Airport } & \multicolumn{3}{|c|}{ Inputs } & \multicolumn{3}{|c|}{ Outputs } \\
\hline & $\begin{array}{l}\text { Airports } \\
\text { Capacity }\end{array}$ & Routes & $\begin{array}{c}\text { Operating } \\
\text { cost }\end{array}$ & $\begin{array}{c}\text { No of } \\
\text { Movements }\end{array}$ & Cargo & Passengers \\
\hline $\mathrm{ABH}$ & 0 & 0 & 0 & 0 & 0 & 0 \\
\hline TUU & 75476 & 3.25 & 0 & 0 & 0 & 200963 \\
\hline TIF & 0 & 2 & 0 & 0 & 995.32 & 1699829 \\
\hline ELQ & 7055 & 0 & 3385396 & 0 & 0 & 140621 \\
\hline HAS & 0 & 0.12 & 0 & 1839 & 0 & 334084 \\
\hline GIZ & 0 & 0 & 0 & 0 & 0 & 0 \\
\hline ABT & 350000 & 0 & 5617282 & 0 & 784 & 42229 \\
\hline WAE & 0 & 0.55 & 1861503 & 0 & 26.67 & 55313 \\
\hline SHW & 0 & 1.11 & 0 & 0 & 75.11 & 259311 \\
\hline TUI & 0 & 0 & 2.5 & 0 & 369.76 & 241502 \\
\hline $\mathrm{BHH}$ & 0 & 0 & 0 & 0 & 0 & 0 \\
\hline RAE & 0 & 0 & 148021.6 & 238 & & 44817 \\
\hline EJH & 0 & 1.78 & 0 & 0 & 514.07 & 213135 \\
\hline $\mathrm{RAH}$ & 0 & 0 & 5386163 & 0 & 569.2 & 240898 \\
\hline EAM & 600000 & 0 & 238619.3 & 0 & 970 & 230954 \\
\hline AQI & 0 & 0.46 & 0 & 0 & 358.47 & 173347 \\
\hline AJF & 0 & 0 & 0 & 0 & 0 & 0 \\
\hline HOF & 0 & 0 & 1 & 0 & 917.58 & 18352.7 \\
\hline URY & 0 & 0 & 4315330.5 & 0 & 0 & 52485 \\
\hline YNB & 0 & 0 & 0 & 0 & 0 & 0 \\
\hline DWD & 50000 & 0 & 4087759 & 0 & 883.1 & 286052 \\
\hline
\end{tabular}




\subsection{Super Efficiency Model}

Table 6 reports the results of the application of the Super efficiency model, which ranks the efficient airports. It indicates that the rank of efficient airport is:

Abha Airport came first with $186.31 \%$, which means that if the outputs decreased by $86.13 \%$ the airport would still on the efficient frontier. The 2nd is Al-Jouf airport with $142.41 \%$, the 3rd is Beisha airport with $138.46 \%$ and the last is Gizan airport with $107.65 \%$

Table 6

\begin{tabular}{|c|c|r|c|}
\hline Airport & $\begin{array}{c}\text { CRS } \\
\text { Score }\end{array}$ & Super Efficiency & Rank \\
\hline AHB & $100.00 \%$ & $186.13 \%$ & $\mathbf{1}$ \\
\hline GIZ & $100.00 \%$ & $107.65 \%$ & $\mathbf{4}$ \\
\hline BHH & $100.00 \%$ & $138.46 \%$ & $\mathbf{3}$ \\
\hline AJF & $100.00 \%$ & $142.41 \%$ & $\mathbf{2}$ \\
\hline
\end{tabular}

\subsection{Airport benchmarking}

The DEA approach allows us to identify for each inefficient airport it's reference set of efficient airports (peer), which use the same inputs in order to produce the same outputs.

Table 7 shows the inefficient airports and their reference sets. For example Tabouk airport is an inefficient airport and its reference set consists of four airports which are Abha $(\lambda 1=0.606)$, Gizan $(\lambda 2=0.27)$, Najran $(\lambda 3=0.109)$ and Al-Qaisomah $(\lambda 4=0.014)$.

Wadi Al-Dawaser and Abha airports are peers for 10 inefficient airports and they can serve as benchmarking (best practice) for inefficient airports.

Table 7: Referance Set

\begin{tabular}{|c|c|c|c|c|c|c|c|c|c|}
\hline \multirow{2}{*}{} & \multicolumn{9}{|c|}{ Reference Airports } \\
\cline { 2 - 10 } & AHB & GIZ & ABT & WAE & BHH & EAM & AQI & AJF & YNB \\
\hline TUU & 0.606 & 0.27 & & & & 0.109 & 0.014 & & \\
\hline TIF & 0.54 & & & 0.437 & 0.023 & & & & \\
\hline ELQ & 0.121 & 0.273 & 0.121 & 0.403 & & & & & 0.082 \\
\hline HAS & 0.361 & & & 0.445 & & & 0.19 & & \\
\hline SHW & 0.205 & & & 0.740 & & & 0.055 & & \\
\hline TUI & 0.129 & & & 0.543 & 0.328 & & & & \\
\hline RAE & 0.044 & & & 0.487 & & & & 0.469 & \\
\hline EJH & 0.117 & & & 0.592 & & & 0.291 & & \\
\hline RAH & & & & 0.63 & & & & & 0.37 \\
\hline HOF & 0.297 & & & 0.366 & 0.337 & & & & \\
\hline URY & 0.086 & 0.032 & & 0.882 & & & & & \\
\hline
\end{tabular}

\section{Conclusion}

This research was aimed at evaluating the performance of Saudi domestic airports. A total of 21 domestic airports were evaluated with the application of Data Envelopment Analysis (DEA) output oriented method. The results of relative efficiency had been found in terms of constant return to scale (CRS) and variable return to scale (VRS). VRS measures the pure technical efficiency (PTE), while CRS is designed to determine the technical efficiency (TE), which is composed of pure technical and scale efficiency. The analysis results indicate that 10 Airports are 100\% (PTE), whereas 4 Airports are $100 \%$ (TE). Four airports were pure technically efficient and scale efficient, this is due to the effect of scale.

It is worth mentioning that the application of DEA model for measuring airports' efficiency is highly dependent on inputs and outputs we consider. In case such inputs and outputs as airport employees, airport revenue, terminals area and number of gates were considered (currently unavailable on the website of GACA), the results of the research would be different. 


\section{Recommendations}

1. DEA is a valuable managerial tool, which allows conducting reliable analysis of performance of airports. So, it is highly advisable that GACA considers the idea of adopting DEA approach to evaluate efficiency of airports' performance.

2. GACA should consider the reasons of inefficiency of some of the airports in Saudi Arabia and elaborate on the ways to tackle existing issues and avoid the appearance of new ones.

3. Future assessments of airports' performance efficiency should be made with consideration of more outputs and inputs, which exert influence on the performance of the airports. For instance, extra data on terminals' area, airports;' employees and the number of gates should be taken into account.

\section{ACKNOWLEDGMENTS}

I would like to express my appreciation to my supervisorDr:Saleh Bin Saban who cheerfully answered my queries,provided me with materials, checked my examples, assisted mein a myriad ways with the writing and helpfully commentedon earlier drafts of this project. Also, I am also very grateful toDr; EsamHabis for his good humor and support throughout the production of this project. My thanks also to the staff in the management of local airports and who gave me the necessary data to write a review of this research.

\section{REFERENCES}

[1] Bowman, M., Debray, S. K., and Peterson, L. L. 1993. Reasoning about naming systems. .

[2] Adler, N., Berechman, J., 2001. Measuring airport quality from the airlines' viewpoint: an application of data envelopment analysis. Transport Policy, 8(3), pp.171-181

[3] Anderson, P., Petersen, N.C., 1993. A procedure for ranking efficient units in data envelopment analysis. Management science, 39, pp.1261-1264

[4] Barros, C.P., Dieke, P.U.C., 2008. Measuring the economic efficiency of airports: A Simar-Wilson methodology analysis. Transportation Research Part E: Logistics and Transportation Review, 44(6), pp. 1039-1051

[5] Bazargan, B., Vasigh, V.,2003. Size versus efficiency: a case study of U.S. commercial airports. Journal of Air Transport Management, 9(3), pp.187-193

[6] Bezić, H., Segota, A.,Vojvodic, K.., 2010. Evaluating airport efficiency using data envelopment analysis. Advances in Business-Related Scientific Research Journal (ABSRJ), 1 (1), pp. 55-66

[7] Charnes A, Cooper, W., Rhodes, E., 1978. Measuring the efficiency of decision making units. European Journal of Operation Research, 2(6), pp. 429-444.

[8] Cook, W.D., Zhu, J., 2008. Data Envelopment Analysis Modeling Operational Processes and Measuring Productivity. Los Angeles: CreateSpace Independent Publishing Platform.

[9] Cooper, W., Seiford, L.M., Kaoru, T., 2007. Data Envelopment Analysis. A Comprehensive Text with Models, Applications, References and DEA-Solver Software. Berlin: Springer

[10] Curi, C., Gitto, S., Mancuso, P.,2008. An application of Data Envelopment Analysis (DEA) to measure the efficiency of the Italian airports after the privatization. L'industria, 4, pp. 689-712

[11] General Authority for Civil Aviation., 2011. Statistical Yearbook 2011. Available at <www.gaca.gov.sa> [Accessed 3 June 2013]

[12] Gillen, D., Lall, A., 1998. Non-parametric measures of efficiency of U.S. airports, Dublin: ATRG Conference

[13] Hovald, T., Graham, A., 2003. Efficiency Measurement for U.K. airports : an application of data envelopment analysis. Oxford: Transport Studies Unit

[14] Koçak, H., 2011. Efficiency Examination of Turkish Airports with DEA Approach. International Business Research, 4(2), pp.204-212

[15] Martin, C.J., Roman, C., 2001. An application of DEA to measure the efficiency of Spanish airports prior to privatization. Journal of Air Transport Management, 7(3), pp.149-157

[16] Oum, T.H., Zhang, A., Zhang, Y.,2008. Ownership forms matter for airport efficiency: a stochastic frontier investigation of worldwide airports. Journal of Urban Economics, 64(2), pp.422-435

[17] Psaraki-Kalouptsidi, V., Kalakou, S., 2011. Assessment of efficiency of Greek airports. Journal of airport management, 5 (2)., pp.170-186

[18] Sarkis, J., 2000. An analysis of the operational efficiency of major airports in the. Journal of Operations Management, 18, pp. 335-351

[19] So, S.H, Kim, J.J., Cho, G., Kim, D.-K., 2007. Efficiency Analysis and Ranking of Major Container Ports in Northeast Asia: An Application of Data Envelopment Analysis. International Review of Business Research Papers, 3(2), pp. 486 - 503. 
[20] Syamsul, R.R., Shah, S. R., 2010. Performance measurement of Malaysian airports using DEA method. Proceedings of Malaysian Universities Transportation Research Forum and Conferences, pp.487-492

[21] Yoshida, Y., Fujimoto, H., 2004. Japanese airports benchmarking with the DEA and endogenous-weight TFP methods: testing the criticism of overinvestment in Japanese regional airports. Transportation Research Part E.: Logistics and Transportation Review, 40(6), pp.533-546

[22] Zhu, J., 2003. Quantitative Models for Performance Evaluation and Benchmarking: Data Envelopment Analysis With Spreadsheets and DEA Excel Solver. Berlin: Springer 